\title{
Work in Progress on the Creation of the Three-Stringed Kulcapi
}

\author{
Panji Suroso $^{1}$, Uyuni Widiastuti ${ }^{2}$, Rahmat Riswan Aidil Syahputra Siregar ${ }^{3}$, Adina S \\ Sembiring ${ }^{4}$, Obed Sembiring ${ }^{5}$, Ewin Johan Sembiring ${ }_{-}^{6}$ \\ 1,2,3,4,5,6Universitas Negeri Medan, Indonesia \\ Email:panjisuroso12@gmail.com
}

\begin{abstract}
This research tittle 'work in progress on the creation of the three-stringed kulcapi' wanted to examine how the work process of the creation of the kulcapi music instrument and can be explained descriptively. The kulcapi musical instrument which is considered to still have limitations in terms of producing its notes, and only having 2 strings, seems to be the cause of the less than optimal function in exploring the notes. In addition, the form of the kulcapi instrument is seen to be still very plain and very simple, this is felt to be one of the issues that must be overcome to be able to explore the kulcapi musical instrument to be more functional, both in producing tones and adding aesthetic value to the form of the kulcapi music instrument. In this research, a qualitative descriptive method is used. The process of tracing data and information is done diachronically to find out in full and complete about the kulcapi music instrument. The data collected comes from two sources, they are primary and secondary data. Primary data obtained through in-depth interviews and participant observation that aims to collect data followed by focus group discussions. This research produces findings including: a) The creation of three-stringed kulcapi instruments has a wider range of tone areas. b) can be functioned more flexible and can be explored in playing pentatonic and diatonic tones. c) The shape has the characteristic of the Karo people with the presence of ethnic Karo ornaments on the kulcapi's body.
\end{abstract}

Keywords: three-stringed kulcapi

\section{Introduction}

Karo is one of the ethnic groups in North Sumatra. Karo Ethnic is one of the five other Batak Ethnic groups, namely, Toba, Karo, Simalungun, Pakpak, Mandailing and Angkola. Each of these ethnic groups has a diverse cultural character and this is passed down from generation to generation from their ancestors since long ago. Ethnic Karo has a tradition of string art called kulcapi. Kulcapi is one of stringed musical instrument that is often used in various cultural activities by the Karo community. Kulcapi has a very simple form made of wood using two catguts or strings.

The Kulcapi's music instrument still seems to has limitations in terms of producing its tones, it is because the kulcapi's musical instrument only has 2 strings. In addition, the shape of the kulcapi's instrument still looks so very plain and simple, this is considered to be one of the discussions that must be resolved to be able to review the kulcapi music instrument become more functional both in producing tones or adding aesthetic value of the Kulcapi music instrument.

In connection with this, it is necessary to conduct an in-depth assessment to obtain the data needed as material in developing the regional tone of the Kulcapi instrument which so far is still considered to have limitations. In addition, it is necessary to add traditional ornaments to the body of the Kulcapi as an identity enhancer that characterizes the Karo ethnicity on the kulcapi instrument. How this research and development is carried out will be discussed in the following sections in a coherent and systematic manner. 


\section{Research Method}

The approach used in this research is a qualitative descriptive approach of the musical instruments creation. The process of searching data and information is worked diachronically to find out about the Kulcapi music instrument fully and completely. The data collected comes from two sources, namely primary data and secondary data. Primary data is obtained through in-depth interviews and participant observation that aims to collect the data followed by focus group discussions.

Another feature is the video camera, photo and audio visual recorder which is very useful in documenting data. The selection of informants is based on the grouping of key informants which includes artists, users, experts and academics of stringed music. The total of informants is not limited as long as the data needed is still needed to answer the purpose of this study. Secondary data is obtained from related institutions and related tradition organizations, such as documents about the existence of traditional musical instruments and so on.

The stages and steps that will be carried out in this study are:

1) Research preparation stage which includes designing proposals, conducting literature studies, determining research topics, formulating problems and research objectives, determining research locations, and establishing research methods.

2) The stage of collecting primary and secondary data. Primary data obtained through in-depth interviews and participant observation which aims to collect data followed by focusing group discussions. Secondary data were obtained from related institutions and related tradition organization, such as documents about the existence of traditional musical instruments and so on.

3) The data analysis stage is worked by categorizing and analyzing primary data and secondary data, conducting discussions with experts. The next step is formulating the 3-string Kulcapi creation concept.

4) The formulation stage of the kulcapi string creation concept 3.

5) The trial phase applying the formulation of the 3-string kulcapi creation concept. The trial process is carried out by preparing material and equipment requirements. Applying the formulation of the 3 string kulcapi concept. Then make corrections and improvements to problems that is transpire. Next set the concept of creation 3-string kulcapi.

6) The production phase of creating 3 string kulcapi instruments is by preparing equipment needs, selecting quality raw materials and making the process of instrument creation products based on the concepts and models of the results of studies that has been carried out.

7) The stage concluding the results and making a report of research findings. At this stage, the results of the research will be summarized, conducted a seminar on the results and the preparation of research reports

\section{Discussion}

\subsection{Analysis of Karo Traditional Kulcapi Organology Data}

The shape structure concept of kulcapi belongs to the long-necked and stringed lute instrument 2. The structure of the kulcapi parts consists of: 1) The Kulcapi's Head, 2) The Kulcapi's Neck, 3) The body or shaft of the Kulcapi as a resonator, 4) the resonator hole. 5) the tail of the Kulcapi 


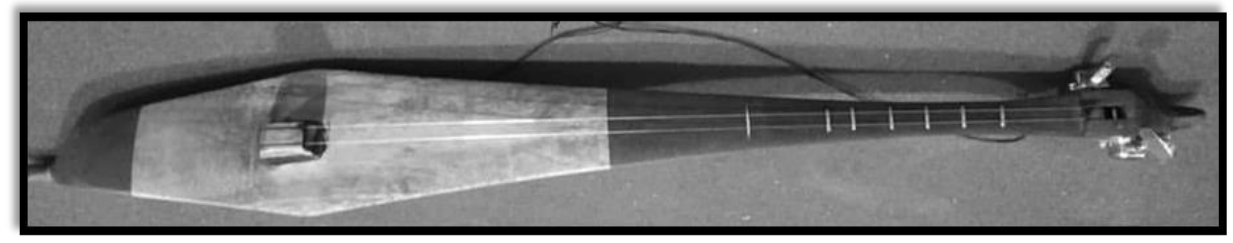

Photograph of the Karo Traditional Kulcapi Instrument

a. The Kulcapi's Head

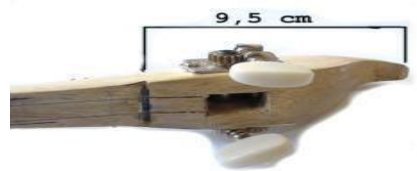

The Kulcapi's Head is head designed with an ornament shaped animal's head with a length of $9 \mathrm{~cm}$ to $9.5 \mathrm{~cm}$. The head is equipped with an acoustic guitar tuning on the right and left sides of the Kulcapi's head as a place to connect the two strings or strings made of metal.

b. The Kulcapi's Neck

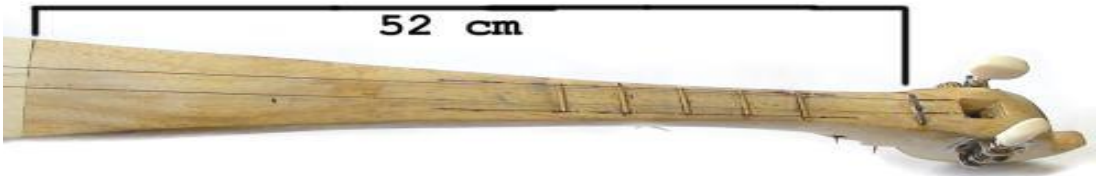

The neck of the kulcapi measures $52 \mathrm{~cm}$ in length and the width of the neck near the tip of the head is $2 \mathrm{~cm}$ in size and the width widens the neck of the kulcapi on the part adjacent with the shaft following the shape of its size approximately $3 \mathrm{~cm}$.

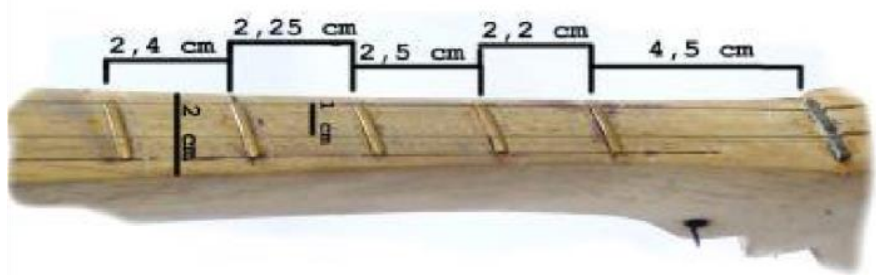

On the neck part, there are segments as a limiting space for the fingering position with each pret distance starting from the part near the head; first pret $4.5 \mathrm{~cm}$, second pret $2.2 \mathrm{~cm}$, third pret $2.5 \mathrm{~cm}$, fourth pret $2.25 \mathrm{~cm}$ fifth pret, $2.4 \mathrm{~cm}$. The distance from one string to the other $1 \mathrm{~cm}$.

c. The Front of Kulcapi's Body

$5 \mathrm{~cm}$

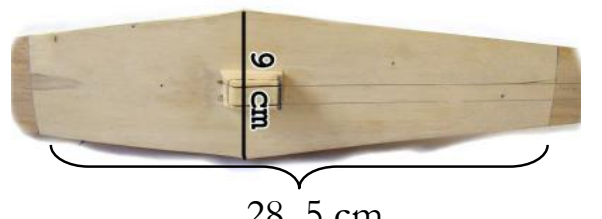

$4 \mathrm{~cm}$

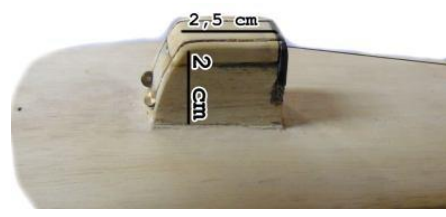

The front of the Kulcapi is the resonator cover found in the kulcapi body as a vibrating chamber which is very influential on the production of the kulcapi sound. The width of the near the tail part is approximately $5 \mathrm{~cm}$, the width of the middle part of the Kulcapi is $9 \mathrm{~cm}$ and the width of the part near the neck is $4 \mathrm{~cm}$. 
d. The Resonator Hole

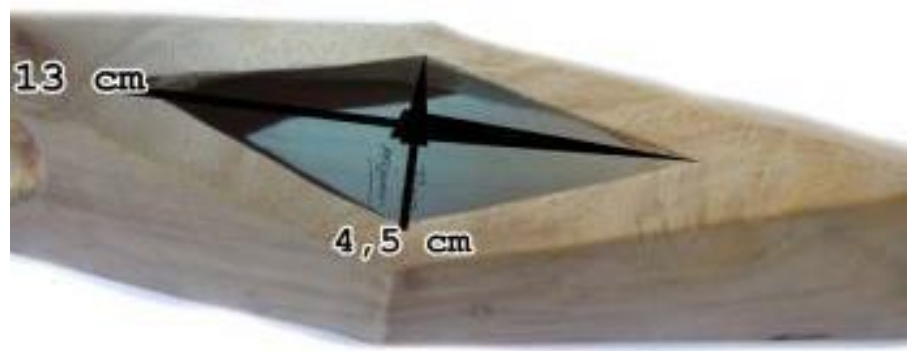

The kulcapi resonator hole is rectangular in shape and is located at the back of the kulcapi body. The resonator hole has a length of $13 \mathrm{~cm}$ and a width of 4.5 .

e. The Kulcapi's Tail

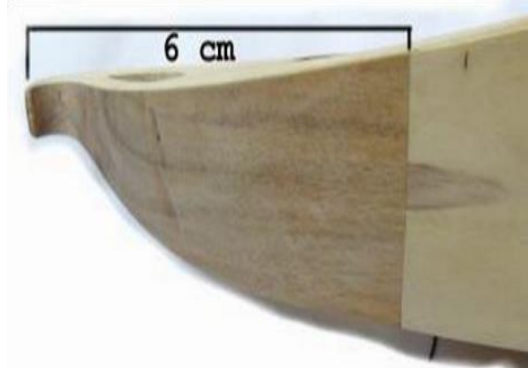

The Kulcapi's tail has a length of $6 \mathrm{~cm}$ in width adjusted to the kulcapi's body and has a tapered end.

f. The Kulcapi’s Inter-String Range

Kulcapi has two strings that are installed from the head to the tip of the body, the width of the two strings is $1 \mathrm{~cm}$ and the range is the do-sol interval (kwin range)

g. The Kulcapi's Gamut.

The Kulcapi's Gamut is G-A-B-C-D-E-Fis-G gamut

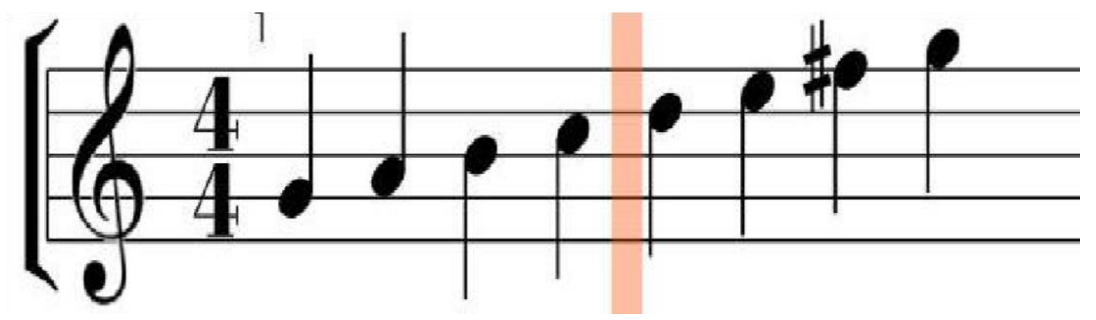

h. There are two Kulcapi’s playing techniques, namely: dila-dila techniques and rengget techniques.

Table 1. Analysis Table

\begin{tabular}{|l|l|l|l|l|}
\hline No & $\begin{array}{c}\text { Name of String } \\
\text { Musical } \\
\text { Instrument }\end{array}$ & $\begin{array}{c}\text { Part of } \\
\text { Ornology } \\
\text { Structure }\end{array}$ & $\begin{array}{c}\text { Description of } \\
\text { Instrument Structure }\end{array}$ & Size Description \\
\hline 1 & Kulcapi & - Head & $\begin{array}{l}\text { Ornament shaped } \\
\text { animal's head }\end{array}$ & $\begin{array}{l}\text { Length }=5 \mathrm{~cm} \\
\text { Width }=3,5-4 \\
\text { cm }\end{array}$ \\
\cline { 3 - 5 } & & - Neck & Long Neck Lude & $\begin{array}{l}\text { Lenght }=52 \mathrm{~cm} \\
\text { Width }=2-4 \mathrm{~cm}\end{array}$ \\
\cline { 3 - 5 } & & &
\end{tabular}




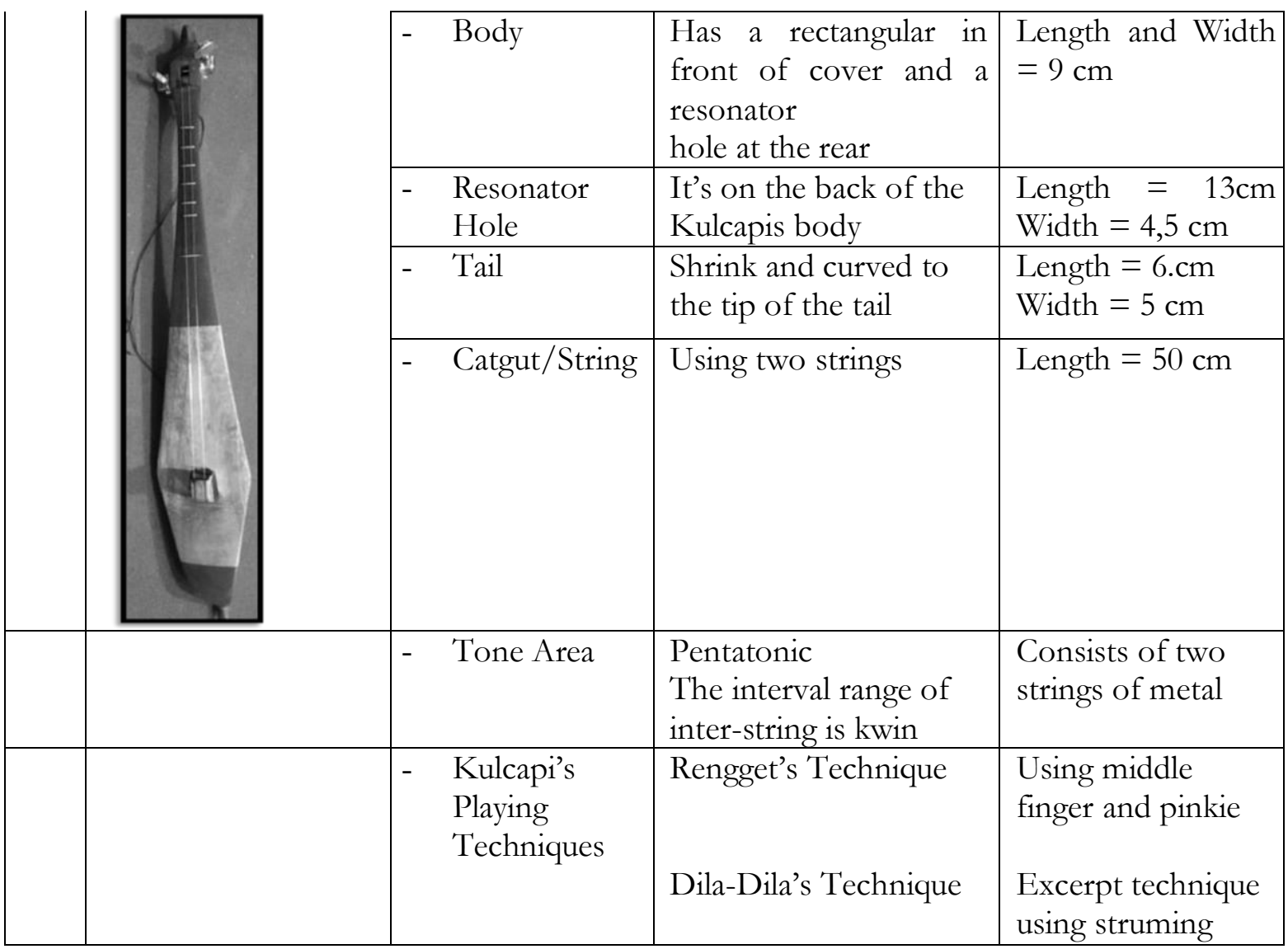

Based on the organological analysis of the kulcapi instrument, there are a number of musical limitations on this instrument, including: the lack of tone area that can be explored because the number of strings is only two and the pret number on the neck of the kulcapi is also minimal. This results in the lack of a wide range of tones that can be produced to meet the need to explore melodic play in reaching broader gamut models. This kulcapi's two strings so far can only play pentatonic melodies and can only reach the traditional melodic model. In addition, the shape is still plain without a touch of traditional karo ornaments that can add aesthetic value to the body of the kulcapi

\subsection{The Formula of Creation of the Three-Stringed Kulcapi Instrument Burned Carving Motives}

a. Part of Head

By considering bringing back the patterns owned by the traditional string instrument by exploring the head elements on the kulcapi instrument into a new concept and having 3 tuning stemers in an effort to bring newness and expand the tone area. b. Part of Neck.

In formulating the concept of neck shape's instrument, the research team explored by bringing back the existing concept, the neck area of the instrument has increased the width to twice the neck width of the previous instrument to accommodate the 3-string concept in expanding the tone area and increasing the number of frets which initially numbered 6 to 9 frets. c. Part of Instrument Body.

At the front, the same thing is done, which is still adopting existing elements and exploring the addition of ornaments to beautify the shape of the front of the body. Considering the quality of the sound produced, the research team still used the old concept of presenting a resonator cover 
at the front of the instrument body. The cover of this resonator is explored by presenting a symbol of Karo ethnicity culture in certain parts. d. Resonator Hole.

The resonator hole will be located on the back still following the old pattern and added three resonator holes that are not too large in the front as an effort to expand the sound of the instrument. e. Part of Tail.

The tail is functionally still a part of the instrument that can be supported on the player's arm. But aesthetically the tail must have the beauty of its shape. In this case the tail is conceptualized in the form that is adopted from the diversity of traditional artepak motifs that are related in a form that has aesthetic value.

\section{f. String/ Catgut}

In the Karo ethnic-based string instrument instrument concept design used three strings / strings from metal and strings from synthetic nylon. The reason why using three strings is to be able to expand the playing range of the tone area and still be able to bring the character (rengget) of Karo ethnicity.

\section{g. Tone Area}

By using three strings / catgut, the tone area clearly tone will be broader covering the area of the related traditional tone, both diatonic tones and pentatonic tones. Each string will be $1 \mathrm{~cm}$ apart, the interval between 1 and 2 strings is kwin, the distance between 2 strings and three strings is quart. This is adjusted to the composition of the interval distance at kulcapi (kwin and kwart string interval intervals). Thus, the playing of the tone region will become wider and more participative in developing melodic shape patterns.

Findings Expansion of the Tone Area

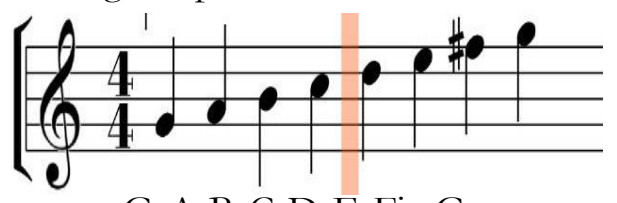

G-A-B-C-D-E-Fis-G

Vit diagram of the kulcapi tone 2 strins

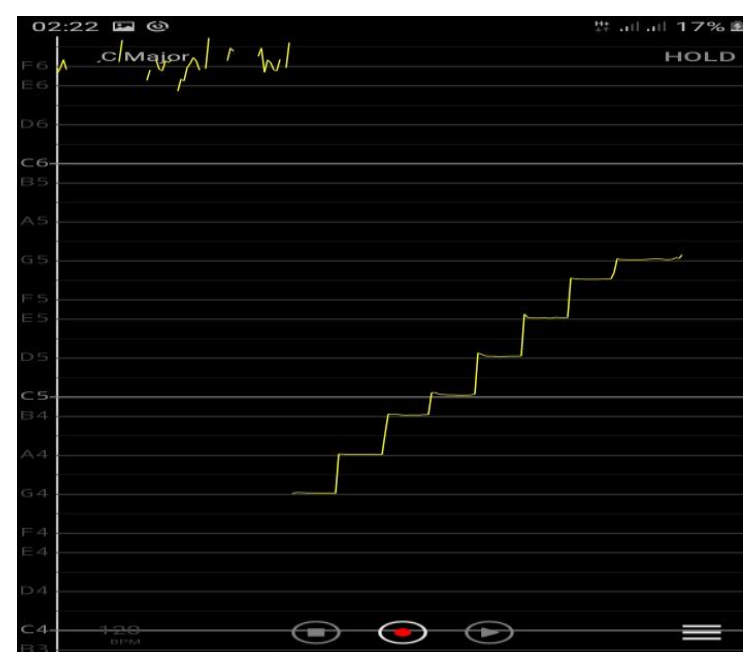

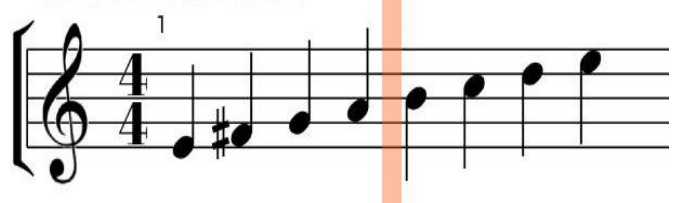

E-Fis-G-A-B-C-D-E-

Vit diagram of the kulcapi tone 3 strings

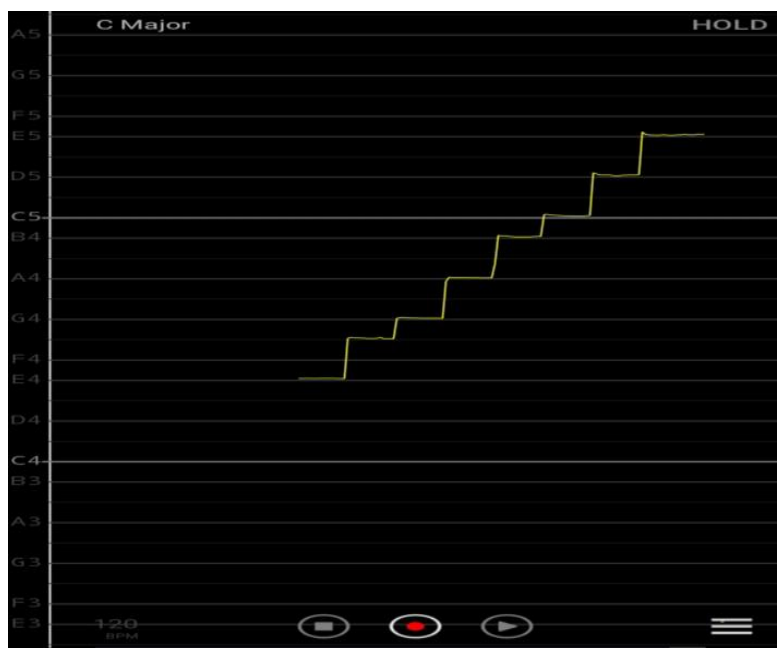




\subsection{The Process of Creation of the Three-Stringed Kulcapi Instrument Burned Carving Motives}

After reviewing, analyzing and formulating the concept of the instrument the research team carried out several stages including:

a. Preparing equipment and raw materials that will be used on the basis of the formulation of the concept of creating stringed musical instruments. The equipment used include: machine drills, wood chisels, saws, machetes, carving knives, grinders, sand paper. The raw material that is used is the type of king wood or wooden timber, this type of wood has good quality in producing sound and easy to do the the formation according to the concept that is formulated.

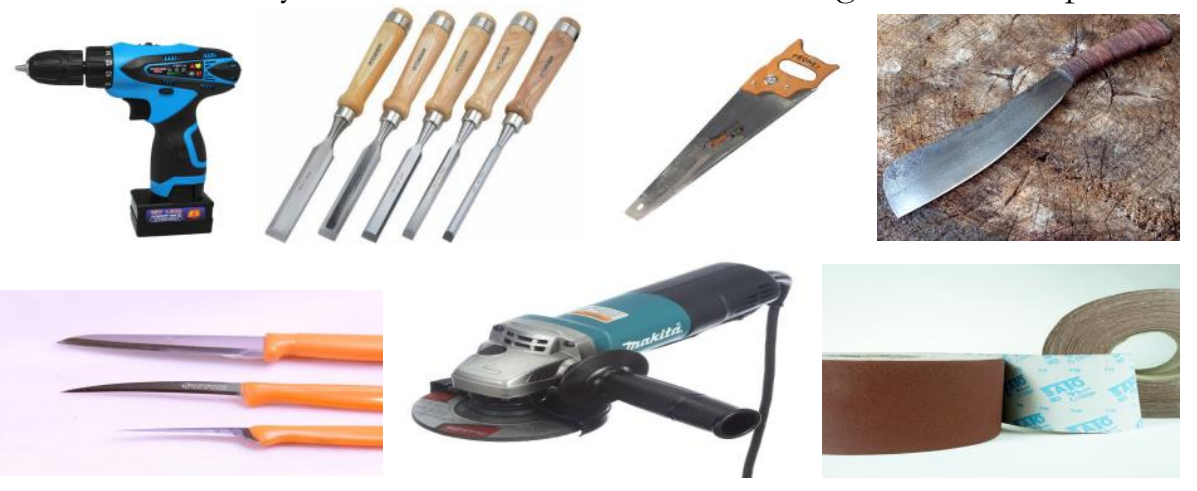

b. After the equipment and raw materials are available, the process of making stringed musical instruments begins to be carried out step by step to produce the desired shape according to the concept. The steps are as follows:

- Formation of kulcapi on wooden blocks

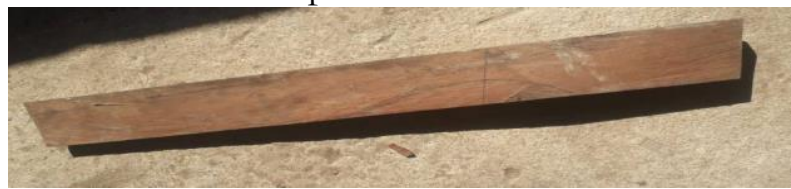

- Formation of the upper body

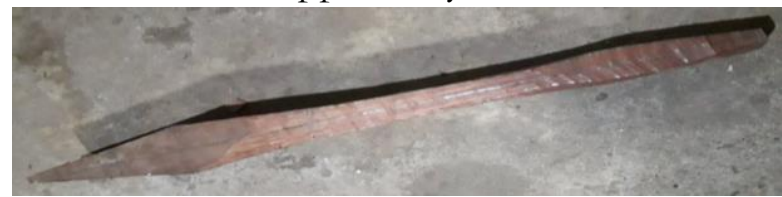

- Formation of the lower body

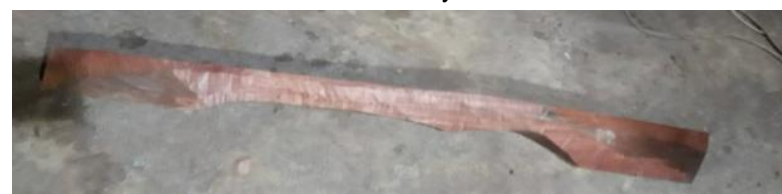

- Formation of a hole in the body

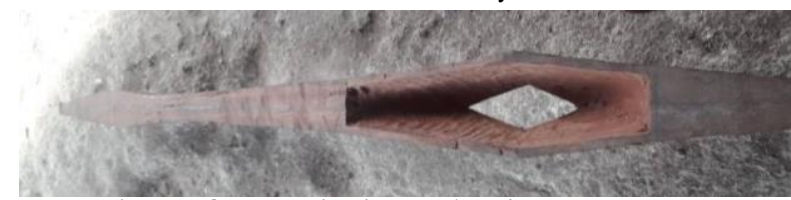

- Formation of a cap hole on body

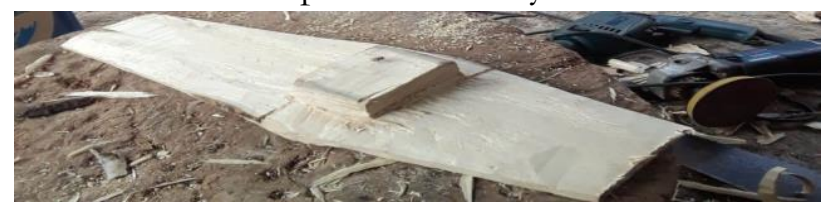


- The process of gluing the cap on the body

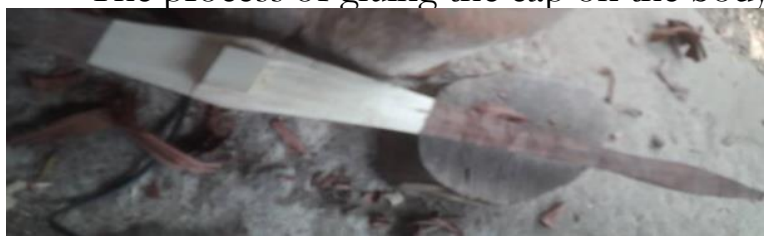

- Installation of fret and tuner
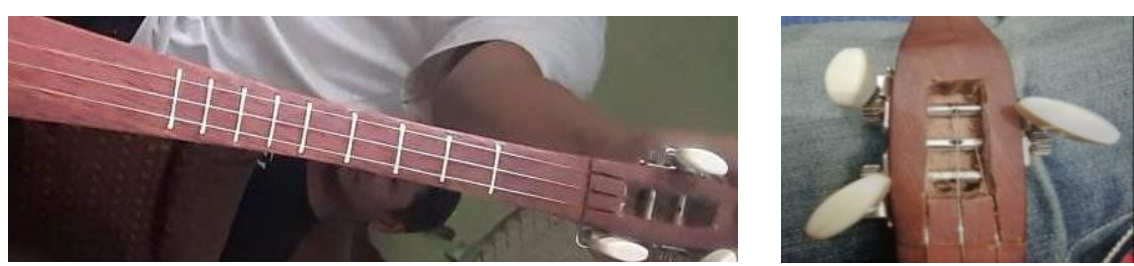

- The three-string kulcapi's full shape appears from the front and from the back
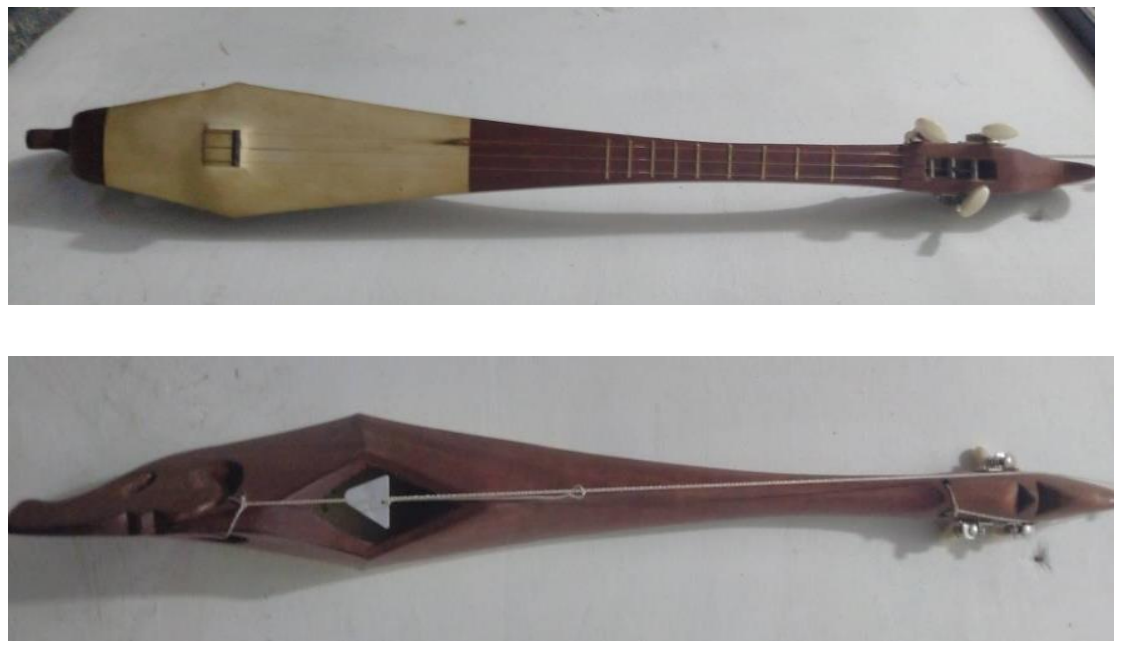

- The process of testing and evaluating the sound of instruments by trying to play several melodic modes and their development

- The revision / repair process. By fixing parts that are considered to has errors or not appropriate to the concept.

- The Process of granting burned carving motives

- The process of installing preamps and finishing all forms of musical instruments.

\section{Conclusion}

a. Based on the organological analysis of the kulcapi instrument, there are a number of musical limitations on this instrument, including: the lack of a region that can be explored because the number of strings is only two and the pret number on the neck of the kulcapi is also minimal. This results in the lack of a wide range of notes that can be produced to meet the need to explore melodic play in reaching broader scale models. Kulcapi two strings so far can only play pentatonic melodies and can only reach the traditional melodic model.

b. The process of creating Kulcapi burned carving motives is carried out by reviewing, analyzing and formulating the instrument form consequences afterwards: preparing equipment and raw materials to be used on the basis of the formula for creating musical instrument picks. The equipment used include: machine drills, wood chisels, saws, machetes, carving knives, grinders, sand paper. The raw material used is the type of king wood or wooden timber, this type of wood has good quality in producing sound and easy to do the formation according to the concept that is formulated. 
c. After the equipment and raw materials are available, the process of making stringed musical instruments begins to be carried out step by step to produce the desired shape according to the concept. The steps are as follows: forming images on the provided beam, forming upper and lower body, forming resonator holes, making resonator manhole covers, installing preters and tuners, testing instruments, making repairs and pinising instruments

d. The 3-string kulcapi instrument has a novelty and several advantages of the two-string kulcapi instrument type. The advantages are;

- Has a broader range of tone

- Can be used to play diatonic tones.

- The shape is more characteristic of the Karo people with the presence of ethnic Karo ornaments

\section{References}

Dian Octavia K. (2014). Struktur Organologi Hasapi dalam Gondang Hasapi Pada grup Musik Etnis Pardomuanta di Surabaya, Apron Jurnal Pemikiran seni Pertunjukan vol 1. No 5 http: // jurnalmahasiswa. unesa.ac.id/ index. php/ apron / article/view/8947/11962.

Hornbostel, Erich M. Von and Curt Sach. (1961). Clasification of Musical Instrument. Translate from original German by Anthony Baines and Klausss P.Wachsmann.

I Made Winarta, Dr.Drs. et al. (2016). PROSES PEMBUATAN GITAR UKIR I WAYAN TUGES DI

DESA GUWANG, KECAMATAN SUKAWATI, KABUPATEN TINGKAT II GIANYAR,

Jurnal Pendidikan Seni Rupa Universitas Pedidikan Ganesha, Vol.5, no 2, https: // ejournal.

undiksha. ac.id / index. php/ JJPSP/ article/ view/ 8052

Merriam, Allan P. (1964). The Antropology of Music. North Western : University Press

Sihotang Batoan L. (2015). Kajian Organologi Kucapi PakPak Buatan Bapak Kami Capah di Kecamatan Kaerajaan Kabupaten PakPak Bharat. Bachelor Thesis Department of Ethnomusicology, Faculty of Cultural Sciences, University of North Sumatra.

Simaremare Gidon. (2015). Kajian Orgonologi Hasapi Batak Toba buatan Guntur Sitohang di Desa Turpuk Limbong Kecamatan Harian Boho Samosir, Bachelor Thesis Department of Ethnomusicology, Faculty of Cultural Sciences, University of North Sumatra.

Sitepu Beri Pana. (2013. Kajian Organologi Kulcapi Pada Masyarakat Karo Buatan Bapak Pauji Ginting Bachelor Thesis Department of Ethnomusicology, Faculty of Cultural Sciences, University of North Sumatra.

Sunarto, B. (2013). Epistemologi Penciptaan Seni, Idea Press Jogjakarta.

Suroso Panji. (2018). Model Creation of Musical String Instrument Based on Ethnic Diversity in North Sumatera. Humanities and Social Sciences Budapest International Risearch and Critics InstituteJournal (BIRCI- Journal) vol 1 no 4 - December - 2018

Tobing Jackry Octora. (2014). Kajian Organologis Alat Musik Gambus Buatan Bapak Syahrial Felani, Bachelor Thesis Department of Ethnomusicology, Faculty of Cultural Sciences, University of North Sumatra. 